\title{
Del(10q23)/PTEN Gene Locus Deletion
}

National Cancer Institute

\section{Source}

National Cancer Institute. del(10q23)/PTEN Gene Locus Deletion. NCI Thesaurus. Code C158865.

A cytogenetic abnormality that refers to the deletion of the chromosomal band 10q23, which also results in the deletion of the PTEN gene. 